\title{
Potencial genético de um sintético de milho de grãos duros para formação de híbridos
}

\author{
Genetic potential of a flint maize synthetic for hybrid production
}

\section{Elto Eugenio Gomes e Gama ${ }^{1}$ Manoel Xavier dos Santos ${ }^{1}$ Romário Gava Ferrão $^{3}$ Walter F. Meireles ${ }^{2}$ Cleso Antônio Patto Pacheco' ${ }^{1}$ Sidney Neto Parentoni² ${ }^{2}$ Paulo Evaristo O. Guimarães ${ }^{1}$}

\section{RESUMO}

O objetivo deste estudo foi determinar através das estimativas de parâmetros genéticos o potencial de um sintético de milho de grãos duros e de ciclo semiprecoce, para a formação de híbridos elou melhoramento intrapopulacional. Foram utilizadas 142 progênies endogâmicas $S_{2}$ do Sin EEL Flint, em cruzamentos topcrosses com um Sintético heteroticamente contrastante. Essas progênies topcrosses foram avaliadas utilizando-se o delineamento em látice simples $12 \times 12$, e em dois locais de teste. Os maiores valores médios para PED foram observados para os topcrosses $n^{\circ} 101$ (12069kg ha- ${ }^{-1}$ e $n^{o} 72(11068 \mathrm{Kg}$ $\mathrm{ha}^{-1}$ ), tendo o primeiro apresentado comportamento especifico para Londrina, e o segunda demonstrado comportamento superior nos dois ambientes. Os valores das estimativas dos parâmetros estudados foram semelhantes aos encontrados em alguns estudos conduzidos em condições tropicais. O grupo de progênies $S_{2}$ da Sin EEL Flint conduziu a valores médios $d e \hat{\sigma}_{p}^{2}$, CVg e $h^{2}$ similares aos encontrados na literatura para outros genótipos. Observa-se que esse Sintético possui suficiente variabilidade genética e potencial para extração de linhagens para formação de hibridos e como germoplasma em programas de melhoramento.

Palavras-chave: parâmetro genético interpopulacionais, produção, Zea mays $L$.

\section{ABSTRACT}

The objective of this study was to determine the genetic potential of a semi-early maize synthetic with flint type kernel (Sin EEL Flint). The estimation of genetic parameters was obtained with $S$, progenies, and the performance of the progenies in hybrid combinations were evaluated. One hundred fourty-two $S$, progenies of Sin EEL Flint were used. They were obtained by top crossings with a contrasting heterotic synthetic of dent type kernel. These topcross progenies were tested in a lattice design $12 \times 12$ with two replications in two locations, Sete Lagoas and Londrina. The selected topcross $n^{\circ} 101$, with specific adaptation for Londrina. and $n^{-7} 7$, being adapted to both locations, were the best yieldings (PED) with $12069 \mathrm{Kg} \mathrm{ha}^{-1}$ and $11068 \mathrm{Kg}$ $h a^{-1}$, respectively. Values of the estimated parameters for $\hat{\sigma}_{p}^{2}$, $\mathrm{CVg}$ and $h^{2}$ were similar to those found in other studies conducted in tropical conditions. It was observed that this synthetic has enough genetic and potential variability to inbred line extraction for hybrid production and to be used as germoplasm source in breeding programs.

Key words: interpopulation genetic parameter, yield, Zea mays $L$.

\section{INTRODUÇÃO}

O melhorista, para o seu trabalho de seleção, deve escolher o germoplasma mais adequado aos seus propósitos. Apesar do limitado número de materiais utilizados, existe uma grande variabilidade genética para caracteres de expressão econômica que pode ser usada nos programas de melhoramento de milho. Nas condições brasileiras, a introdução de novos germoplasma tanto tem contribuído sobremaneira para o crescimento do potencial de produção em relação às cultivares tradicionais, como tem possibilitado a incorporação de genes para conferir resistência às principais pragas e doenças (MIRANDA FILHO, 1992; REGITANO NETO, 1997).

\footnotetext{
${ }^{1}$ Engenheiro Agrônomo, PhD, Pesquisador, Embrapa Milho e Sorgo, CP151, 35701-970, Sete Lagoas, MG, Email: gamaelto@cnpms.embrapa.br. Autor para correspondência.

${ }^{2}$ Engenheiro Agrônomo, MSc, Pesquisador, Embrapa Milho e Sorgo, CP 151, 35701-970, Sete Lagoas, MG

${ }^{3}$ Engenheiro Agrônomo, MSc, Pesquisador, INCAPER, CP 151, 39900-000, Linhares, ES.
} 
Além da caracterização morfológica, é necessário que sejam estimados os parâmetros genéticos do germoplasma (MARQUEZ-SANCHEZ \& HALLAUER, 1970). Assim, vários estudos de estimativas de parâmetros genéticos já foram realizados com diferentes tipos de populações de milho (LAMKEY \& HALLAUER, 1987; SOUZA JÚNIOR, 1989; PANDEY \& GARDNER, 1992; TAVARES, 1997; GAMA et al.,1999).

O principal objetivo do melhorista em seus trabalhos é selecionar genótipos superiores dentro de uma determinada população. Assim, as técnicas experimentais de seleção a serem aplicadas devem permitir uma identificação e a avaliação de genótipos, em menor tempo e custo possíveis. DAVIS (1927), LINDSTRON (1931) e JENKINS \& BRUNSON (1932) sugeriram que, na avaliação de um elevado número de linhagens, essas deveriam ser avaliadas em "topcross", visando eliminar materiais que não tenham méritos consideráveis para que seja promovida a sua seleção, tornando, desta forma, mais racionais e eficientes os trabalhos de desenvolvimento de híbridos e sintéticos.

O objetivo deste trabalho foi determinar, através de três características de importância agronômicas e das estimativas de parâmetros genéticos, o potencial de um sintético de milho de grãos duros para a formação de híbridos e/ou melhoramento intrapopulacional.

\section{MATERIAL E MÉTODOS}

Em 1992, a cultivar sintética de milho Sin EEL Flint teve sua formação iniciada no Embrapa Milho e Sorgo por meio de recombinações de progênies $S_{1}$ extraídas da população CMS 05. Na EEL, Estação Experimental de Linhares- ES, após passar por vários ciclos de seleção massal estratificada, essa população recebeu a introgressão (25\%) de germoplasma Cateto. Este sintético passou por três ciclos de recombinação, seguido de mais três ciclos de melhoramento com progênies de meios irmãos com seleção para aumentar a prolificidade e, também, para tolerância ao acamamento e às principais doenças foliares. O Sin EEL Flint apresenta ciclo intermediário e estatura média de planta, possuindo grãos duros de coloração alaranjada.

A partir de 1996, um grupo de progênies endogâmicas extraídas deste sintético, foram avaliadas em ensaios conduzidos na área experimental da Embrapa Milho e Sorgo, Sete Lagoas, MG. As melhores progênies selecionadas foram plantadas em fileiras pareadas, onde, por ocasião do florescimento, avançou-se a endogamia para o nível de $\mathrm{S}_{2}$. Dos resultados experimentais obtidos no ano agrícola 1996/ 97, constatou - se uma heterose significativa entre dois sintéticos formados pelo melhoramento de milho da EMBRAPA, Sin EELFlint e SINDENTE. O SINDENTE foi formado a partir da recombinação de 16 linhagens elites do programa de melhoramento, extraídas da população CMS 06, com a introgressão de $12,5 \%$ de material temperado para melhoria do padrão da espiga.

No início de 1997, foi plantado um lote isolado de despendoamento, utilizando-se como macho um Sintético de grãos dentados (SINDENTE) e tendo como fêmeas as progênies $\mathrm{S}_{2}$ do Sin EEL Flint contrastantes. Assim, obtiveram-se 142 progênies de meios irmãos interpopulacionais do Sin EEL Flint cruzado com o SINDENTE.

No ano agrícola 1997/98, estas progênies foram avaliadas em dois locais: Sete Lagoas (MG) e Londrina (PR). Foi utilizado o delineamento em látice simples 12 x 12 com duas repetições e duas testemunhas (SINDENTE e o híbrido simples C 333B). A parcela constituiu-se de uma fileira de $5 \mathrm{~m}$, com espaçamento de 0,90 e $0,20 \mathrm{~m}$ entre e dentro das fileiras, respectivamente. Por ocasião da colheita, foram tomados dados de produção de espigas despalhadas (PED) em kg parcela ${ }^{-1}$, alturas de planta (AP) e de espiga (AE).

Os componentes da variância foram estimados de acordo com as esperanças matemáticas dos quadrados médios, segundo o delineamento de látice ou blocos casualizados conforme metodologia proposta por VENCOVSKY \& BARRIGA (1992).

\section{RESULTADOS E DISCUSSÃO}

Os valores dos CV (Tabela 1) encontrados neste estudo situaram entre $6,17 \%$ a $16,55 \%$, valores estes considerados de aceitável magnitude por PIMENTEL GOMES (1985) e, também, por SCAPIM et al. (1995) que, em levantamento baseado em 66 teses na área de genética e melhoramento de milho, encontraram um valor médio de CV de $16,2 \%$ para o caracter peso de espigas despalhadas (PED).

A análise conjunta da variância para $o$ caracter PED mostrou significância para progênies e para a interação progênies e locais. A significância da interação progênies x locais para este caracter, indica que as performances das progênies nos dois locais não devem ser consistentes, principalmente devido à grande variabilidade genética que é esperada dentro dos topcrosses das progênies $\mathrm{S}_{2}$, tanto per se, como em cruzamento. Interação significativa entre esses dois locais, também foi demonstrada por PELLICANO (1990). 
Tabela 1 - Médias para produção de espigas despalhadas em $\mathrm{kg} \mathrm{ha}^{-1}(\mathrm{PED})$, alturas de planta (AP) e de espigas(AE), para as 20 melhores topcrosses do Sin EEL Flint com o SINDENTADO. Embrapa Milho e Sorgo, Sete Lagoas, 2002.

\begin{tabular}{|c|c|c|c|c|c|c|c|}
\hline \multicolumn{4}{|c|}{ Londrina } & \multicolumn{4}{|c|}{ Sete Lagoas } \\
\hline Topcross** & PED & $\mathrm{AP}$ & $\mathrm{AE}$ & Topcross & PED & $\mathrm{AP}$ & $\mathrm{AE}$ \\
\hline 101 & 12069 & 247 & 134 & 72 & 11068 & 228 & 135 \\
\hline 19 & 11076 & 237 & 116 & 36 & 10091 & 235 & 138 \\
\hline 112 & 10789 & 265 & 124 & 123 & 9798 & 250 & 143 \\
\hline 30 & 10383 & 247 & 144 & 55 & 9634 & 253 & 138 \\
\hline 72 & 10138 & 250 & 118 & 98 & 9634 & 253 & 148 \\
\hline 142 & 9826 & 255 & 134 & 143 & 9446 & 200 & 125 \\
\hline 25 & 9504 & 244 & 149 & 50 & 9404 & 198 & 115 \\
\hline 82 & 9503 & 250 & 142 & 97 & 9298 & 243 & 153 \\
\hline 67 & 9476 & 229 & 126 & 118 & 9008 & 223 & 128 \\
\hline 129 & 9346 & 231 & 118 & 137 & 8970 & 245 & 138 \\
\hline 65 & 9345 & 229 & 131 & 75 & 8904 & 240 & 143 \\
\hline 75 & 9308 & 255 & 131 & 33 & 8658 & 213 & 123 \\
\hline 54 & 9289 & 237 & 121 & 112 & 8634 & 255 & 140 \\
\hline 137 & 9257 & 247 & 129 & 43 & 8486 & 243 & 143 \\
\hline 5 & 9196 & 260 & 144 & 19 & 8404 & 228 & 128 \\
\hline 140 & 9163 & 244 & 136 & 25 & 8396 & 233 & 125 \\
\hline 119 & 9102 & 224 & 136 & 63 & 8314 & 215 & 128 \\
\hline 38 & 9065 & 237 & 147 & 13 & 8150 & 223 & 128 \\
\hline 107 & 8976 & 234 & 118 & 46 & 7976 & 258 & 143 \\
\hline 84 & 8917 & 255 & 147 & 7 & 7888 & 240 & 140 \\
\hline $\begin{array}{l}\text { Média } \\
\text { selec. }\end{array}$ & 9686 & 244 & 132 & $\begin{array}{l}\text { Média } \\
\text { selec. }\end{array}$ & 9008 & 233 & 137 \\
\hline Média geral & 7642 & 241 & 136 & $\begin{array}{c}\text { Média } \\
\text { geral }\end{array}$ & 6651 & 230 & 132 \\
\hline $\mathrm{CV}(\%)$ & 16,55 & 7,54 & 11,18 & $\mathrm{CV}(\%)$ & 15,63 & 6,17 & 10,53 \\
\hline Sindente* & 7320 & 218 & 110 & Sindente* & 6132 & 212 & 108 \\
\hline C 333B* & 12054 & 243 & 139 & C 333B* & 11525 & 239 & 142 \\
\hline
\end{tabular}

**Topcrosses coincidentes em negrito

Os valores médios para PED $\left(\mathrm{kg} \mathrm{ha}^{-1}\right)$ das 20 melhores progênies topcrosses selecionadas dos cruzamentos entre o Sin EEL Flint e o SINDENTE, computados dos dados obtidos em Sete Lagoas (MG) e Londrina (PR), encontram-se na tabela 1. Considerando-se as progênies selecionadas, observase que houve um número baixo $(30 \%)$ de progênies topcrosses coincidentes entre Londrina e Sete Lagoas, indicando o efeito da interação com o ambiente o qual poderia ser explicado em parte pela própria constituição do material genético avaliado e , também, pelas condições dissimilares de instalação dos ensaios dos dois ambientes.
O desempenho médio de produtividade das melhores progênies topcrosses Sin EEL Flint (S ) x SINDENTE selecionadas em Sete Lagoas e Londrina foi, respectivamente, $19,64 \%$ e $21,84 \%$ inferior ao híbrido simples testemunha $\mathrm{C} 333 \mathrm{~B}$, porém em relação à testemunha SINDENTE apresentou uma produtividade média de $24,43 \%$ e $31,93 \%$ superior, respectivamente para os dois locais. $\mathrm{Na}$ análise por local (Tabela 1), os maiores valores médios encontrados para PED foram observados para os topcrosses no $101\left(12069 \mathrm{~kg} \mathrm{ha}^{-1}\right)$ e no $72\left(11068 \mathrm{~kg} \mathrm{ha}^{-1}\right)$, tendo o primeiro apresentado comportamento específico para Londrina e o segunda demonstrado comportamento superior nos dois ambientes. No caso do melhorista ter de escolher para o seu trabalho de produção de híbridos: para Londrina, a melhor opção recairia sobre a progênie de $n^{\circ} 101$ e para Sete Lagoas a de $\mathrm{n}^{-} 72$ por apresentarem maiores produções e apresentarem AP e AE semelhantes à média das progênies dos ensaios. Ainda assim, com relação a esses dois caracteres de alta herdabilidade, verificase que os híbridos topcrosses possuem porte semelhantes ao híbrido simples comercial (C 333B), utilizado como testemunha, sendo uma boa indicação do potencial de competitividade desses híbridos. Os topcrosses selecionadas apresentaram valores semelhantes de AP e AE para os dois locais, porém a AP foi um pouco superior em Londrina do que em Sete Lagoas. Uma vez que os híbridos topcrosses apresentaram produções semelhantes ao do híbrido simples comercial, verifica-se o elevado potencial deste sintético para um programa de híbridos de linhagens.

Os resultados encontrados neste estudo vêm corroborar com HALLAUER \& MIRANDA FILHO (1988) que, em estudo com diferentes testadores salientaram a importância de ser usado como testador de famílias endogâmicas uma população de grupo heterótico diferente. Possivelmente, a aplicação desse resultado, para a utilização desses sintéticos na produção de linhagens e de híbridos, seria de grande valia no melhoramento. Assim, COMSTOCK (1964) afirmou que o desempenho de um híbrido interpopulacional (topcross) representa o comportamento médio de todos os tipos de híbridos possíveis oriundos de cruzamentos entre linhagens endogâmicas das populações parentais. Portanto, a presença de um híbrido topcross muito produtivo, mostra que se podem obter híbridos superiores de cruzamentos entre linhagens endogâmicas das populações testadas.

Na tabela 2, são apresentados os parâmetros genéticos e fenotípicos para PED, do Sin EEL Flint. Em se tratando da variância genética entre os topcrosses 
Tabela 2 - Estimativas dos parâmetros genéticos e fenotípicos dos topcrosses formados pelos cruzamento de $142 \mathrm{~S}_{2}$ da população Sin EEL Flint com a população SINDENTE para peso de espigas despalhadas $\left(\mathrm{g}_{\text {planta }}{ }^{-1}\right)$. Embrapa Milho e Sorgo, Sete Lagoas, 2002.

\begin{tabular}{lcc}
\hline \multirow{2}{*}{ Componente } & \multicolumn{2}{c}{ Estimativa } \\
\cline { 2 - 3 } & Sete Lagoas & Londrina \\
\hline$\hat{\sigma}_{p}^{2}$ & 11,72 & 21,33 \\
$\hat{\sigma}_{\bar{F}}^{2}$ & 910,45 & 782,40 \\
$\mathrm{CVg}$ & 7,19 & 3,69 \\
$\mathrm{~h}^{2}(\%)$ & 22,71 & 13,73 \\
$\mathrm{~b}$ & 0,27 & 0,16 \\
\hline
\end{tabular}

$\hat{\sigma}_{p}^{2}=$ Variância genética entre topcrosses

$\hat{\sigma}_{\bar{F}}^{2}=$ Variância fenotípica média entre topcrosses

$\mathrm{CVg}=$ Coeficiente de variação genética entre as médias dos topcrosses

$\mathrm{h}^{2}(\%)=$ Coeficiente de herdabilidade no sentido amplo

$\mathrm{b}=$ Quociente entre CVg e CVe

avaliados ( $\hat{\sigma}_{p}^{2}$, as estimativas envolvendo as $\mathrm{S}$ e a população contrastante como testadora são variânécias genéticas interpopulacionais conforme VENCOVSKY (1987). Quando se compara as estimativas da variância genética interpopulacional, resultantes de progênies de grãos duros (Sin EEL Flint) cruzadas com o testador de grãos dentados, (SINDENTE), observa-se que o valor da $\hat{\sigma}_{p}^{2}$ foi maior em Londrina que em Sete Lagoas, apesar do fato de as estimativas estarem superestimadas pela presença do componente da interação topcrosses x locais. Comparando-se as estimativas de $\hat{\sigma}_{p}^{2}$, quando se usa progênies de grãos duros como fêmea e um Sintético contrastante de grãos dentados como macho para obtenção das progênies topcrosses, pode ser observado que o testador foi positivo para liberação de variabilidade. Este resultado foi semelhante ao encontrado por TAVARES (1997) que concluiu que a liberação da variabilidade, utilizando-se testadores não relacionados, é maior do que quando se utiliza a própria população.

A estimativa da variância fenotípica média entre topcrosses $\left(\hat{\sigma}_{\bar{F}}^{2}\right)$ foi maior em Sete Lagoas que em Londrina nas análises individuais para os topcrosses formados pelas $\mathrm{S}_{2}$ do Sin. EEL Flint com o testador SINDENTE de grãos dentados. Isso indica, portanto, a importância da contribuição de outras fontes de variações que não somente a $\hat{\sigma}_{p}^{2}$.

Segundo LAMKEY \& HALLAUER (1987), estimativas de herdabilidade permitem aos melhoristas calcularem o progresso esperado com seleção relacionados com fontes de germoplasma, bem como o método de melhoramento e a quantidade de testes a serem empregados. De acordo com as observações constatadas para $\hat{\sigma}_{p}^{2}$, os valores médios das estimativas da herdabilidade $\left(\mathrm{h}^{2}\right)$ foram maiores para os topcrosses em Sete Lagoas (22,71\%) que em Londrina (13,73\%). Este resultado foi semelhante ao relatado por PELLICANO (1990), no qual as estimativas das herdabilidades médias de famílias para seleção interpopulacional, para a cultivar BR 105 de grãos duros, foi de $24 \%$ e $21 \%$ em Londrina e S. Lagoas, respectivamente, indicando a possibilidade de sucesso com seleção recorrente interpopulacional.

Ainda que exista interação genótipo $\mathrm{x}$ ambiente, isto não implica diretamente que o melhoramento deva ser feito separadamente para cada local, uma vez que a magnitude das estimativas de $h^{2}$ do caráter, poderá permitir progressos significativos com a seleção, melhorando o híbrido interpopulacional para ambas regiões.

As progênies topcrosses formadas entre Sin EEL (S ) x SINDENTE tiveram um valor médio para o coeficiente de variação experimental (CVe) um pouco maior que o valor do coeficiente de variação genético $(\mathrm{CVg})$, resultando num valor estimado para $b=0,54$, que indica uma situação não muito favorável para a seleção de acordo com VENCOVSKY \& BARRIGA, 1992.

Quanto às estimativas dos componente da variância interpopulacional, os resultados encontrados na literatura são em menor número de que para intrapopulacional envolvendo famílias de meios irmãos (VENCOVSKY \& BARRIGA, 1992). Entretanto, como mostraram alguns resultados de trabalhos conduzidos no Brasil, mencionados por PELLICANO (1990), existe suficiente variabilidade aditiva interpopulacional que é a variabilidade importante para se ter sucesso na seleção (HALLAUER \& MIRANDA FILHO, 1988), para a formação de híbridos.

\section{CONCLUSÃO}

As elevadas produtividades dos híbridos topcrosses, aliadas à alta magnitude da variabilidade genética, com a viabilidade de serem obtidos híbridos de linhagens de elevada produtividade, indicam o potencial desse sintético de grãos duros para ser utilizado em programas para obtenção de híbridos de milho.

Ciência Rural, v. 33, n. 4, jul-ago, 2003. 


\section{REFERÊNCIAS BIBLIOGRÁFICAS}

COMSTOCK, R.E. Selection procedures in corn improvement. In: ANNUAL CORN \& SORGHUM INDUSTRY RESEARCH CONFERENCE, 19, Chicago, 1964. Proceedings. Washington : ASTA, 1964. p.12-23.

DAVIS, R.L. Report of the plant breeder. Puerto Rico : Agr. Exp. Sta., 1927. p.14-15.

GAMA, E.E.G. et al. Variabilidade genética no nos sintéticos de milho SIN 53 e SIN 61 para fins de melhoramento. Revista Ceres, v.46, n.268, p.615-624, 1999.

HALLAUER, A.R.; MIRANDA FILHO, J.B. Quantitative genetics in maize breeding. 2.ed. Ames : Iowa State University, 1988. 468p.

JENKINS, M.T.; BRUNSON, A.M. Methods of testing inbred lines of corn in crossbreeding combinations. Journal American Society Agronomy, Madison, v.14, p.523-530, 1932.

LAMKEY, K.R.; HALLAUER, A.R. Heritability estimated from recurrent selection experiment in maize. Maydica, v.32, n.1, p.61-78, 1987.

LINDSTRON, E.W. Prepotency of inbred lines on commercial varieties of maize. Journal American Society Agronomy, Madison, v.23, p.652-661, 1931.

MARQUEZ-SANCHEZ, F.; HALLAUER, A.R. Influence of sample size on the estimation of genetic variances in a synthetic variety of maize, I.grain yield. Crop Science, v.10, n.4, p.357-361, 1970 .

MIRANDA FILHO, J.B. Exotic germplasm introduced in a Brazilian maize breeding program. Brazilian Journal of Genetics, v.15, p.631-642, 1992.

PANDEY, S.; GARDNER, C.O. Recurrent selection for population variety, in hybrid improvement in tropical maize.
Advance in Agronomy, v.48, p.81-87, 1992.

PELlicAno, I.J. Potencial da interpopulação de milho (Zea mays L.) Br 105 x Br 106 para melhoramento genético. 1990. 139f. Dissertação (Mestrado em Genética e Melhoramento) - Curso de Pósgraduação em Genética e Melhoramento, USP/ESALQ.

PENA NETO, A.M. Avaliação da capacidade de progênies S2 obtidas de compostos de milho (Zea mays L.). 1982. 62f. Dissertação (Mestrado em Genética e Melhoramento) Curso de Pós-graduação em Genética e Melhoramento, Escola Superior de Agricultura de Lavras.

PIMENTEL GOMES, F. Curso de estatística experimental. 5.ed. Piracicaba : Nobel, 1985. 466p.

REGITANO NETO, A.; NASS, L. L.; MIRANDA FILHO, J. B. Potential of twenty germplasm maize archteture. Brazilian Journal of Genetics, v.20, p.691-696, 1997.

SCAPIM, C.A.; CARVALHO, C.G.P.; CRUZ, C.D. Uma proposta de classificação dos coeficientes de variação para a cultura do milho. Pesquisa Agropecuária Brasileira, Brasília, v.30, n.5, p.683-686, 1995.

SOUZA JUNIOR, C.L. Componentes da variância genética e suas implicações no melhoramento vegetal. Piracicaba : FEALQ, 1989. 159p.

TAVARES ELIAS, H. Comparação de testadores na avaliação de famílias S2 de milho (Zea mays L.). 1997. 61f. Dissertação (Mestrado em Genética e Melhoramento) Curso de Pós-graduação em Genética e Melhoramento, Universidade Federal de Lavras.

VENCOVSKY, R.; BARRIGA, P. Genética biométrica no fitomelhoramento. Ribeirão Preto : SBG, 1992. 486p.

VENCOVSKY, R. Herança quantitativa. In: PATERNIANI, E.; VIÉGAS, G.P. Melhoramento e produção de milho 2.ed. Campinas : Fundação Cargill, 1987. p.137-274. 